\title{
Endoscopic treatment for gastroesophageal reflux disease: Should you learn the techniques?
}

\author{
Julia J Liu MD FRCPC FACP FACG
}

G astroesophageal reflux disease (GERD), commonly J known as heartburn, is the most common and expensive digestive disease (1). It is a major public health problem, with $20 \%$ of the adult population reporting weekly heartburn symptoms (2). Severe GERD is a major risk factor for esophageal adenocarcinoma (3). Treatment options for GERD consist of medications that reduce acid secretion (antisecretory agents), antireflux surgeries devised to restore the normal anatomy of the gastroesophageal junction (GEJ) and, more recently, endoscopic interventions.

The antireflux barrier at the GEJ is anatomically and physiologically complex, which makes it vulnerable to a number of potential mechanisms of reflux. The two main patterns of lower esophageal sphincter (LES) dysfunction are hypotensive LES and pathological transient LES relaxations (tLESRs) (4,5). Anatomic disruption of the GEJ, commonly associated with a hiatal hernia, is another mechanism that contributes to reflux disease by impairing LES function. tLESRs account for a majority of reflux events in individuals with normal LES pressure and mild reflux disease. The frequency of tLESRs increase with progressive gastric distension, particularly in patients with GERD and hiatal hernia (6). Low LES pressure and hiatal hernia are the predominant mechanisms for patients with severe reflux disease (7).

Medical therapy is chronic and long-term for patients suffering from GERD, particularly for patients with erosive esophagitis; over $80 \%$ of patients will relapse if antisecretory therapies are terminated (8-10). Thus, the same medication that induces remission is usually required in the same dosage to maintain remission $(8,11,12)$. Antisecretory agents, however, do not address the underlying pathophysiological issues of GERD (ie, LES dysfunction and hiatal hernia).

Antireflux surgery has been performed since the early 1950s. The most widely performed procedure today is laparoscopic Nissen fundoplication. The goal of antireflux surgery is to mechanically restore the normal GEJ via open (transthoracic or transabdominal) or laparoscopic approaches, thus to reconstruct the physiological equivalent of normal LES and normalize reflux parameters (13). Other procedures such as Hill, Belsey and Toupe repairs have all been devised to offer antireflux surgeries for specific patient populations. For open fundoplication procedures, a symptomatic response of $80 \%$ to
$90 \%$ has been reported at 10-year follow-up (14). For laparoscopic fundoplication, a similar success rate of $85 \%$ to $90 \%$ has been reported (15-17). Complications following fundoplications include dysphagia $(18,19)$, chest pain, gasbloat syndrome, postoperative hyperflatulence, vagal nerve injuries leading to gastroparesis and diarrhea. The prevalence of postoperative complications ranges from $5 \%$ to $20 \%$ (20). Early postoperative dysphagia can occur in up to $18 \%$ of patients, while late dysphagia can occur in $6 \%$ of patients at two years (21). Therefore, a less invasive mechanical treatment option for GERD may be a very attractive option for patients.

Advances in endoscopic technologies have introduced new therapeutic options for GERD. Since 2000, the Food and Drug Administration (FDA) has approved several endoscopic devices for clinical use. These treatment modalities can be categorized into three groups: radiofrequency ablation of the GEJ with the Stretta catheter (Curon Medical Inc, USA) (22); suturing of the GEJ using either mucosal sutures with the EndoCinch device (Davol Inc, USA) (23) or full thickness suture placement with the NDO plicator (NDO Inc, USA) (24); and finally, injection of bulking materials into the distal esophagus with the Enteryx polymer (Boston Scientific Inc, USA) (25). Enteryx was withdrawn from the market in 2005 due to safety concerns.

The first endoscopic antireflux device that was approved by the FDA was the EndoCinch device. The procedure is called an endoluminal gastroplication, where mucosal plications or pleats are created in a circumferential or longitudinal fashion on the gastric side of the GEJ. The procedure takes between $30 \mathrm{~min}$ and $60 \mathrm{~min}$ to perform, depending on the number of mucosal plications placed and the experience of the endoscopist.

Anatomical and physiological evaluations of the LES after endoluminal gastroplication have been performed to understand the antireflux mechanism of the procedure. Functional changes in the LES in patients with GERD were investigated by Tam et al (26). They found that the placement of two circumferential sutures $1 \mathrm{~cm}$ below the GEJ led to an increase in LES pressure. The $24 \mathrm{~h}$ esophageal acid exposure was also reduced, as well as the frequency of tLESRs six months after the procedure (26). The mucosal sutures were found to induce focal smooth muscle hypertrophy in the distal esophagus in patients with GERD, as well as in a swine model (27). A two-year follow-up study (28) reported that $52 \%$ of patients 
remained symptom free; although esophageal acid exposure was significantly reduced, normalization could not be achieved in the majority of patients. In a nonrandomized study comparing transesophageal endoscopic plication with laparoscopic fundoplication, endoscopic suturing achieved good results; however, more studies would be needed (29).

Full-thickness plications can be created using the NDO plicator. This is the first endoscopic treatment method that demonstrated significant improvement in esophageal acid exposure compared with the sham group (24). Complications seen in 78 patients who underwent the Plicator procedure included two patients with pneumoperitoneum and one patient undergoing exploratory laparoscopy three months later (24). Studies on the mechanism of action for the Plicator procedure are limited.

Temperature-controlled radiofrequency ablation of the cardia using the Stretta catheter was the second antireflux procedure approved by the FDA. For the Stretta procedure, a probe is positioned at the GEJ and the radiofrequency energy is delivered circumferentially to the distal esophagus and the gastric cardia (22). The procedure takes $40 \mathrm{~min}$ to $60 \mathrm{~min}$ to perform.

The antireflux mechanisms of the Stretta procedure have been shown to be related to increased gastric yield pressure in a botox-treated swine model (30) and a reduction in postprandial tLESR (31), as well as a trend toward lower tLESR induced by gastric air distension (32) in patients with GERD. Three-year follow-up results showed that $60 \%$ of patients who had more than $50 \%$ reduction in proton pump inhibitor use showed improvement in esophageal acid exposure (33).

Injection of bulking agents into the muscularis propria layer of the distal esophagus is the third endoscopic approach for patients with GERD. This results in a polymer precipitating in the muscle layer. The mechanism of action is believed to be due to decreased distensibility of the cardia and increased yield pressure (34). A two-year follow-up study showed that $67 \%$ of patients who were off proton pump inhibitors had a $31 \%$

\section{REFERENCES}

1. Sandler RS, Everhart JE, Donowitz M, et al. The burden of selected digestive diseases in the United States. Gastroenterology 2002;122:1500-11.

2. Locke GR III, Talley NJ, Fett SL, Zinsmeister AR, Melton LJ III. Prevalence and clinical spectrum of gastroesophageal reflux: A population-based study in Olmsted County, Minnesota. Gastroenterology 1997;112:1448-56.

3. Lagergren J, Bergstrom R, Lindgren A, Nyren O. Symptomatic gastroesophageal reflux is a strong risk factor for esophageal adenocarcinoma. N Engl J Med 1999;340:825-31.

4. Dent J, Dodds WJ, Friedman RH, et al. Mechanism of gastroesophageal reflux in recumbent asymptomatic human subjects. J Clin Invest 1980;65:256-67.

5. Dodds WJ, Dent J, Hogan WJ, et al. Mechanisms of gastroesophageal reflux in patients with reflux esophagitis. N Engl J Med 1982;307:1547-52.

6. Kahrilas PJ, Shi G, Manka M, Joehl RJ. Increased frequency of transient lower esophageal sphincter relaxation induced by gastric distention in reflux patients with hiatal hernia. Gastroenterology 2000;118:688-95.

7. Barham CP, Gotley DC, Mills A, Alderson D. Precipitating causes of acid reflux episodes in ambulant patients with gastro-oesophageal reflux disease. Gut 1995;36:505-10.

8. Hetzel DJ, Dent J, Reed WD, et al. Healing and relapse of severe peptic esophagitis after treatment with omeprazole. Gastroenterology 1988;95:903-12.

9. Bate CM, Booth SN, Crowe JP, et al. Omeprazole $10 \mathrm{mg}$ or $20 \mathrm{mg}$ once daily in the prevention of recurrence of reflux oesophagitis. Solo Investigator Group. Gut 1995;36:492-8. reduction in esophageal acid exposure (25). In 2005, Enteryx was withdrawn from the market by the manufacturer following reports of serious complications associated with the injection procedures.

Randomized, sham-controlled studies have been performed for all three treatment modalities; however, most studies involve small numbers of patients with high sham response rates and no benefits on esophageal acid exposure. Moreover, the long-term clinical results for these procedures have been disappointing. Therefore, the initial enthusiasm for these new endoscopic treatment options has waned as the experience with the devices has grown.

The performance of these procedures requires additional training for the endoscopist. The device manufacturers, as well as the American Society for Gastrointestinal Endoscopy, have put together seminars and hands-on training sessions to facilitate the education of endoscopists on the performance of these procedures. The average time for an antireflux procedure is between $30 \mathrm{~min}$ and $90 \mathrm{~min}$. Additional equipment such as fluoroscopy may be needed for injection of polymers. Endoscopic suturing procedures may also require deeper level of sedation than the conscious sedation used for routine endoscopy.

The main concerns about all endoscopic antireflux modalities are related to long-term clinical efficacy and safety. Although GERD is a common disorder, adverse events from medical therapy is rare. Serious complications, including death, have been reported with the use of Stretta catheter and Enteryx polymer injection.

It would be reasonable to conclude that endoscopic antireflux therapy is still in the preliminary developmental stage, with significant uncertainty with respect to the clinical efficacy and safety for patients with GERD. The relative efficacy of endoscopic treatment is unclear compared with medical and surgical therapy. Therefore, most gastroenterologists in practice do not yet need to learn the techniques of endoscopic antireflux treatment.

10. Robinson M, Lanza F, Avner D, Haber M. Effective maintenance treatment of reflux esophagitis with low-dose lansoprazole. A randomized, double-blind, placebo-controlled trial. Ann Intern Med 1996;124:859-67.

11. Dent J, Yeomans ND, Mackinnon M, et al. Omeprazole v ranitidine for prevention of relapse in reflux oesophagitis. A controlled double blind trial of their efficacy and safety. Gut 1994;35:590-8.

12. Vigneri S, Termini R, Leandro G, et al. A comparison of five maintenance therapies for reflux esophagitis. N Engl J Med 1995;333:1106-10.

13. Peters JH, DeMeester TR, Crookes P, et al. The treatment of gastroesophageal reflux disease with laparoscopic Nissen fundoplication: Prospective evaluation of 100 patients with "typical" symptoms. Ann Surg 1998;228:40-50.

14. DeMeester TR, Bonavina L, Albertucci M. Nissen fundoplication for gastroesophageal reflux disease. Evaluation of primary repair in 100 consecutive patients. Ann Surg 1986;204:9-20.

15. Bittner HB, Meyers WC, Brazer SR, Pappas TN. Laparoscopic Nissen fundoplication: Operative results and short-term follow-up. Am J Surg 1994;167:193-8.

16. Collard JM, de Gheldere CA, De Kock M, Otte JB, Kestens PJ. Laparoscopic antireflux surgery. What is real progress? Ann Surg 1994;220:146-54.

17. Walker SJ, Baxter ST, Morris AI, Sutton R. Review article: Controversy in the therapy of gastro-oesophageal reflux disease - long-term proton pump inhibition or laparoscopic anti-reflux surgery? Aliment Pharmacol Ther 1997;11:249-60. 
18. Mathew G, Watson DI, Myers JC, Holloway RH, Jamieson GG. Oesophageal motility before and after laparoscopic Nissen fundoplication. Br J Surg 1997:84:1465-9.

19. Jamieson GG, Watson DI, Britten-Jones R, Mitchell PC, Anvari M. Laparoscopic Nissen fundoplication. Ann Surg 1994:220:137-45

20. Vakil N, Shaw M, Kirby R. Clinical effectiveness of laparoscopic fundoplication in a U.S. community. Am J Med 2003;114:1-5.

21. Watson DI, Jamieson GG, Baigrie RJ, et al. Laparoscopic surgery for gastro-oesophageal reflux: Beyond the learning curve. Br J Surg 1996;83:1284-7.

22. Triadafilopoulos G, Dibaise JK, Nostrant TT, et al. Radiofrequency energy delivery to the gastroesophageal junction for the treatment of GERD. Gastrointest Endosc 2001;53:407-15.

23. Filipi CJ, Lehman GA, Rothstein RI, et al. Transoral, flexible endoscopic suturing for treatment of GERD: A multicenter trial. Gastrointest Endosc 2001;53:416-22.

24. Rothstein R, Filipi C, Caca K, et al. Endoscopic full-thickness plication for the treatment of gastroesopahgeal reflux disease: A randomized, sham-controlled trial. Gastroenterology 2006;131:704-12

25. Cohen LB, Johnson DA, Ganz RA, et al. Enteryx implantation for GERD: Expanded multicenter trial results and interim postapproval follow-up to 24 months. Gastrointest Endosc 2005;61:650-8.

26. Tam WC, Holloway RH, Dent J, Rigda R, Schoeman MN. Impact of endoscopic suturing of the gastroesophageal junction on lower esophageal sphincter function and gastroesophageal reflux in patients with reflux disease. Am J Gastroenterol 2004:99:195-202.
27. Liu JJ, Glickman JN, Carr-Locke DL, Brooks DC, Saltzman JR. Gastroesophageal junction smooth muscle remodeling after endoluminal gastroplication. Am J Gastroenterol 2004;99:1895-901

28. Chen YK, Raijman I, Ben-Menachem T, et al. Long-term outcomes of endoluminal gastroplication: A U.S. multicenter trial. Gastrointest Endosc 2005;61:659-67.

29. Mahmood Z, Byrne PJ, McMahon BP, et al. Comparison of transesophageal endoscopic plication (TEP) with laproscopic Nissen fundoplication (LNF) in the treatment of uncomplicated reflux disease. Am J Gastroenterol 2006;101:431-6.

30. Utley DS, Kim M, Vierra MA, Triadafilopoulos G. Augmentation of lower esophageal sphincter pressure and gastric yield pressure after radiofrequency energy delivery to the gastroesophageal junction: A porcine model. Gastrointest Endosc 2000;52:81-6.

31. Tam WC, Schoeman MN, Zhang Q, et al. Delivery of radiofrequency energy to the lower oesophageal sphincter and gastric cardia inhibits transient lower oesophageal sphincter relaxations and and gastro-oesophgeal reflux in patients with reflux disease. Gut 2003;52:479-85.

32. DiBaise JK, Brand RE, Quigley EM. Endoluminal delivery of radiofrequency energy to the gastroesophageal junction in uncomplicated GERD: Efficacy and potential mechanism of action. Am J Gastroenterol 2002;97:833-42.

33. Lutfi RE, Torquati A, Kaiser J, Holzman M, Richards WO. Three year's experience with the Stretta procedure: Did it really make a difference? Surg Endosc 2005;19:289-95.

34. Mason RJ, Hughes M, Lehman GA, et al. Endoscopic augmentation of the cardia with a biocompatible injectable polymer (Enteryx) in a porcine model. Surg Endosc 2002;16:386-91. 


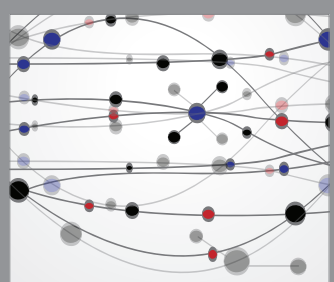

The Scientific World Journal
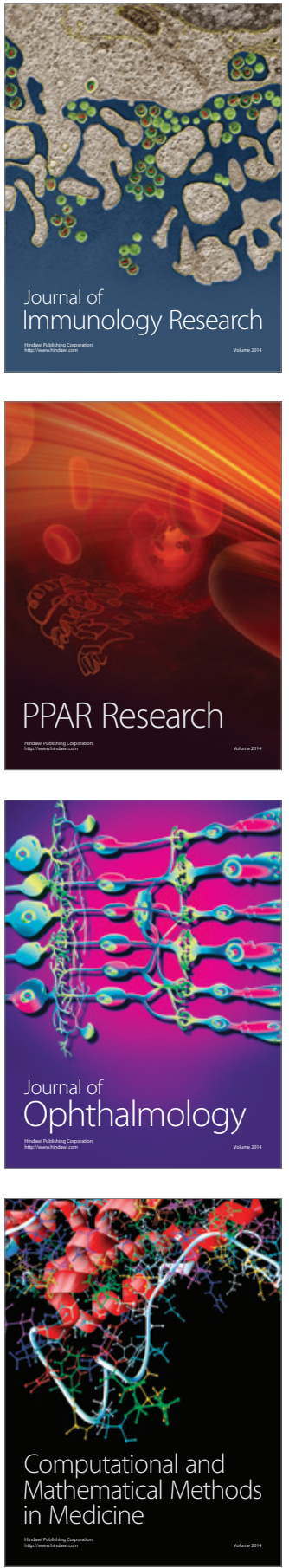

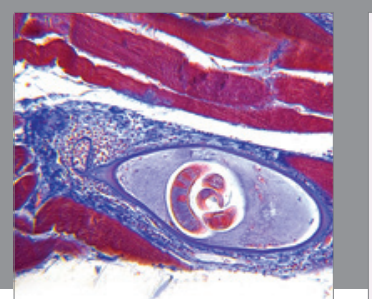

Gastroenterology Research and Practice

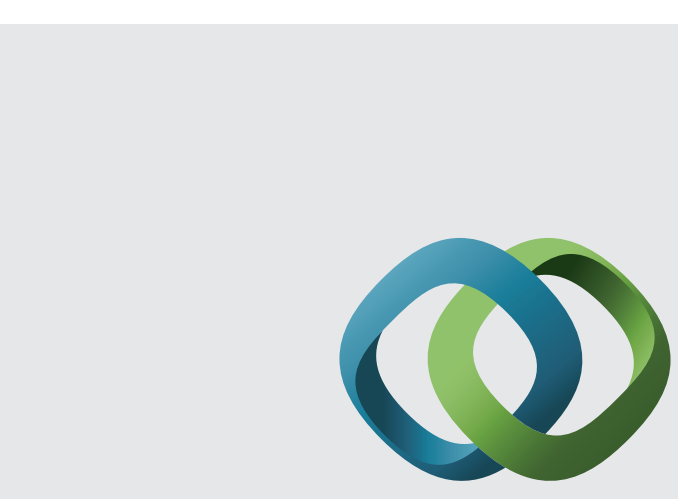

\section{Hindawi}

Submit your manuscripts at

http://www.hindawi.com
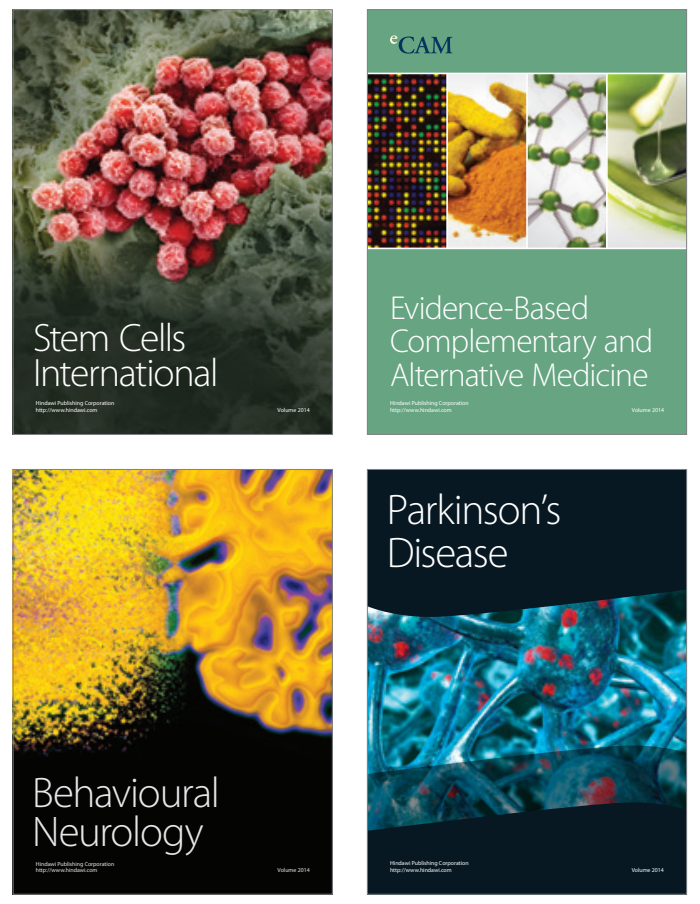
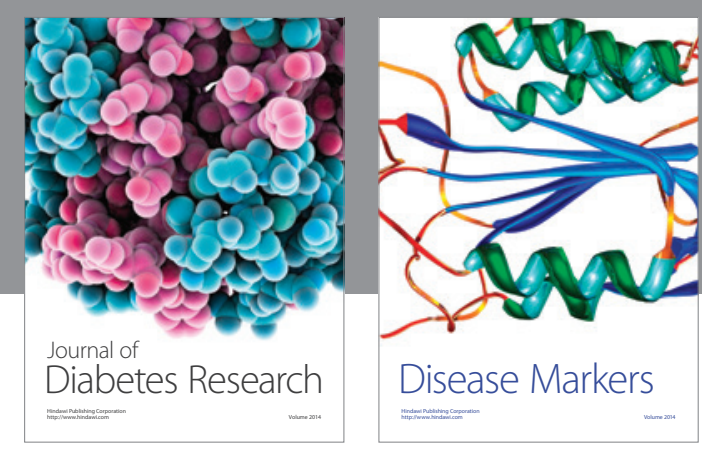

Disease Markers
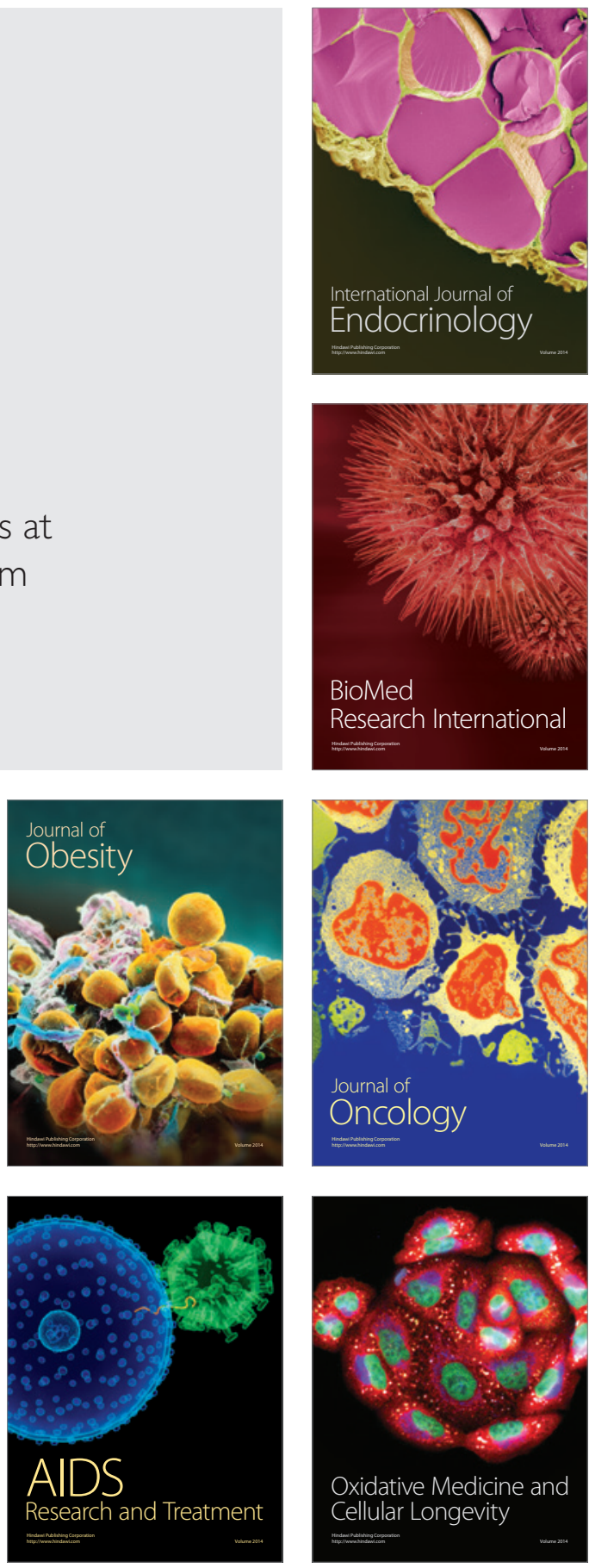